\title{
A Meta-Analysis of Enteral Nutrition and Total Parenteral Nutrition in Patients with Acute Pancreatitis
}

\author{
Heming Quan, Xingpeng Wang, and Chuanyong Guo \\ Department of Gastroenterology, Tenth People's Hospital, Tongji University, Shanghai 200072, China \\ Correspondence should be addressed to Chuanyong Guo, guochuanyong@hotmail.com
}

Received 20 February 2011; Accepted 28 March 2011

Academic Editor: Michel Kahaleh

Copyright () 2011 Heming Quan et al. This is an open access article distributed under the Creative Commons Attribution License, which permits unrestricted use, distribution, and reproduction in any medium, provided the original work is properly cited.

Objective. To analyze the effect of total parenteral nutrition (TPN) and enteral nutrition (EN) in patients with acute pancreatitis. Methods. Randomized controlled trials of TPN and EN in patients with acute pancreatitis were searched in NCBI and CBM databases and The Cochrane Controlled Trials Register. Six studies were enrolled into the analysis, and the details about the trial designs, characters of the subjects, results of the studies were reviewed by two independent authors and analyzed by STATA 11.0 software. Results. Compared with TPN, EN was associated with a significantly lower incidence of pancreatic infection complications $(\mathrm{RR}=0.556,95 \% \mathrm{CI} 0.436 \sim 0.709, P=.000)$, MOF $(\mathrm{RR}=0.395,95 \% \mathrm{CI} 0.272 \sim 0.573, P=.003)$, surgical interventions $(\mathrm{RR}=0.556,95 \% \mathrm{CI} 0.436 \sim 0.709, P=.000)$, and mortality $(\mathrm{RR}=0.426,95 \% \mathrm{CI} 0.238 \sim 0.764, P=.167)$. There was no statistic significance in non-pancreatitis-related complications ( $\mathrm{RR}=0.853,95 \%$ CI $0.490 \sim 1.483, P=.017)$. However, EN had a significantly higher incidence of non-infection-related complications ( $\mathrm{RR}=2.697,95 \%$ CI $1.947 \sim 3.735, P=.994)$. Conclusion. EN could be the preferred nutrition feeding method in patients with acute pancreatitis.

\section{Introduction}

Acute pancreatitis is an inflammatory process that presents different severity degrees, ranging from a mild self-limited disease, with interstitial edema in the pancreas, to a severe disease with extensive necrosis [1]. Severe AP with its related systemic inflammatory response (SIR) causes increased metabolic demands and may progress to multiorgan disease (MOD). Cigarette smoking is an independent risk factor for AP (95\% confidence interval 1.48 to 3.09 ) and total exposure correlates with overall risk [2]. Recurrent attacks of alcoholic AP, however, were not associated with cigarette smoking [3] but occurred less frequently in those who had repeated 6-month counselling sessions (to encourage sobriety) compared with a single session ( $8 \%$ versus $21 \%$, $P=.042)[4]$. These data reinforce the common sense approach of encouraging drinking cessation.

The clinical course of an attack of AP varies from a short period of hospitalization with supportive care to prolonged hospitalization and admittance to an intensive care unit (ICU) because of the development of systemic inflammatory response syndrome (SIRS), multiorgan failure (MOF), and septic complications. Overall, in about $15 \%$ to $20 \%$ of patients, AP progresses to a severe illness with a prolonged disease course. These severely ill patients may develop organ failure and/or local complications such as pancreatic necrosis. Approximately $75 \%$ of the patients have mild disease with mortality below $1 \%$ [5]. Mortality increases up to $20 \%$ if the disease progresses to its severe necrotizing form [6-11], and in the most severe cases mortality can range from 30 to $40 \%[12,13]$. In severe necrotising pancreatitis, $80 \%$ of all patients are catabolic, with high energy expenditure and enhanced protein catabolism. The negative nitrogen balance can be as much as $40 \mathrm{~g} /$ day and can have a deleterious effect on both nutritional status and disease progression [1416]. The traditional treatment strategy is total parenteral nutrition (TPN) giving the inflamed pancreas a rest. Thus, nutritional supply is easily controlled, and adynamic ileus and pancreatic stimulation are avoided. However, in addition to cost and the risk of catheter-related sepsis, TPN may worsen the inflammatory process, lead to metabolic and electrolyte disturbances, alter gut barrier due to increased intestinal permeability, and develop sepsis and multiple organ failure [17]. 
Many high-quality studies have demonstrated that EN results in clinically relevant and statistically significant risk reduction of infectious complications, pancreatic infections, and mortality in patients with predicted severe acute pancreatitis. EN has also been shown to be beneficial as an adjunct to the management of severe acute pancreatitis by obviating the systemic inflammatory response syndrome and in modifying the course of the disease. On the other hand, TPN has a deleterious effect on the intestinal barrier function. Studies performed on animals and human beings show that TPN may worsen intestinal atrophy and intestinal and systemic immunity, and thereby it may also contribute to impair the intestinal mucosa permeability and facilitate bacterial translocation [1]. The protective role of $\mathrm{EN}$, compared with parenteral nutritional $(\mathrm{PN})$, in maintaining the integrity of the gut barrier has been demonstrated in a rat model of acute pancreatitis. The EN group was found to have significantly less bacterial translocation and a lower blood endotoxin level than the PN group.

Data of randomized controlled trials have compared the effect of TEN and TPN. But the results are always not the same and the effect of therapeutics is still not identified because of the small sample sizes. Here, we conducted metaanalysis comparing enteral nutrition with parenteral nutrition to determine the incidence of complications associated with these different routes of nutritional support [18].

\section{Methods and Materials}

2.1. Inclusion Criteria. All clinical randomized controlled trials are performed on adults with predicted severe acute pancreatitis and reported in English. In each case, the definition of the complication was taken as that given in the primary trial. The safety outcome included at least one of the following: pancreatitis-related complications, non-pancreatitisrelated complications, non-infection-related complications, multiple-organ failure (MOF), surgery intervention, hospital stay, and mortality.

2.2. Exclusion Criteria. The comparison not between TPN and EN, such as the comparison in TPN, EN and other traditional trials. The outcome included none of the above.

2.3. Material Collection. We collected all the studies of randomized controlled trials that compared the effect of TEN and TPN. Data from full-text articles were retrieved and checked for consistency by two of us (Heming Quan and Chuanyong Guo) independently. The NCBI (19662010) and CBM (2005-2010) databases and The Cochrane Controlled Trials Register [19] were cross-searched for articles. A bibliographic search in the databases was made using the following predefined terms: (acute [All Fields] AND severe [All Fields] AND ("pancreatitis" [MeSH Terms] OR "pancreatitis" [All Fields]) AND ("enteral nutrition" [MeSH Terms] OR ("enteral" [All Fields] AND "nutrition" [All Fields]) OR “enteral nutrition” [All Fields])) OR ((“jejunum” [MeSH Terms] OR “jejunum” [All Fields] OR "jejunum" [All Fields]) AND ("enteral nutrition" [MeSH
Terms] OR ("enteral” [All Fields] AND "nutrition" [All Fields]) OR "enteral nutrition" [All Fields] OR ("tube" [All Fields] AND "feeding" [All Fields]) OR "tube feeding”[All Fields])) OR (nasogastric [All Fields] AND ("enteral nutrition" [MeSH Terms] OR ("enteral” [All Fields] AND "nutrition" [All Fields]) OR "enteral nutrition" [All Fields] OR ("tube" [All Fields] AND "feeding" [All Fields]) OR "tube feeding" [All Fields])) AND ("humans" [MeSH Terms] AND Clinical Trial [ptyp] AND English [lang] AND “2000/01/1" [PDat] : "2010/12/31" [PDat]). Six randomized controlled trials from six countries were included in our study.

2.4. Quality Evaluation. The methodologic quality of the studies was assessed using a previously published scoring system, with a quality scale range of 0 to 5 points according to Jadad score system $[16,20]$. This quality scale incorporates method of randomization, masking, and dropouts and withdrawals. A score of 2 or less represents a low-quality study, whereas a score of at least 3 represents a high-quality study. The results of Jadad score are presented in Table 2.

2.5. Data Collection. The following parameters were extracted: design of trials, population, incidence of pancreatitis, way of nutrition support, and the outcome of these criteria. We calculated the incidence of pancreatitis according to APACHE II score, the level of CRP, and the incidence of CT. The population statistics results included in the study are presented in Tables 1(a) and 1(b). The effective endpoints of every trial are presented in Table 3.

2.6. Data Analysis. We analyzed pancreatitis-related complications, non-pancreatitis-related complications, non-infection-related complications, surgery intervention, multiple-organ failure (MOF), and mortality between TEN and TPN. The data analysis and graphs were performed using the $\mathrm{M}-\mathrm{H}$ model with STATA 11.0 (Stata Corp., College Station, Tex, USA). We tested heterogeneity between trials with $\chi^{2}$ tests, with $P \leq .01$ indicating significant heterogeneity. The relative risk (RR) was presented with $95 \%$ confidence interval (CI) for dichotomous data using $\mathrm{M}-\mathrm{H}$ model. Besides, hospital stay was analyzed as a continuous variable.

\section{Results}

Of 138 articles screened, 9 RCTs comparing EN and TPN were identified. Only 6 RCTs [20, 22-26] fulfilled the criteria in the meta-analysis. 6 RCTs were included because: (1) an Acute Physiology and Chronic Health Evaluation (APACHE II) score $\geq 8$; (2) trial group received TEN and control group received TPN; (3) effective ends include one of pancreatitis-related complications, non-pancreatitis-related complications, non-infection-related complications, surgery intervention, multiple-organ failure (MOF), and mortality. Five of the six studies are high-quality studies [21]. Random generation: two studies were opaque envelopes, one study was odd/even numbers, and two studies were computerized 
TABle 1

(a) Study characteristics of the included trials

\begin{tabular}{lccccccc}
\hline Authors & \multirow{2}{*}{ Years } & \multirow{2}{*}{ Country } & \multirow{2}{*}{ No. Patients (EN/PN) } & APACHE II score (EN/PN) & Age (EN/PN) & $\begin{array}{c}\text { Gender (EN/PN) } \\
\text { Male }\end{array}$ \\
& & & & & $11.8 / 12.7$ & $65.3 / 59.0$ & $6 / 9$ \\
Female \\
\hline Louie [23] & 2005 & UK & $10 / 18$ & $12 / 12.5$ & $51 / 52$ & $27 / 24$ & $8 / 10$ \\
Petrov [25] & 2006 & Russia & $35 / 34$ & $10 / 9$ & $71 / 68$ & $10 / 14$ & $14 / 12$ \\
Gunilla [24] & 2006 & Sweden & $24 / 26$ & $>8$ & $61.2 / 55.6$ & $8 / 8$ & $3 / 3$ \\
Casas [26] & 2007 & Spain & $11 / 11$ & $>8$ & $38.4 / 41.1$ & - & - \\
Doley [20] & 2009 & India & $25 / 25$ & $14 / 16$ & $52 / 54$ & $32 / 21$ & $30 / 24$ \\
Wu [22] & 2010 & China & $53 / 54$ & &
\end{tabular}

(b) Study characteristics of the included trials

\begin{tabular}{lccccl}
\hline \multirow{2}{*}{ Authors } & \multirow{2}{*}{ Years } & \multicolumn{2}{c}{ Biliary etiology (EN/PN) } & Others & Ways of nutritional support \\
\hline Louie & 2005 & $5 / 7$ & $2 / 4$ & $3 / 7$ & Nasojejunal feeding tube, endoscopy \\
Petrov & 2006 & $11 / 13$ & $16 / 15$ & $8 / 6$ & Nasojejunal feeding tube, X-ray \\
Gunilla & 2006 & $14 / 17$ & $3 / 4$ & $7 / 5$ & Nasogastric feeding tube \\
Casas & 2007 & $4 / 7$ & $1 / 4$ & $6 / 0$ & Nasojejunal feeding tube, endoscopy \\
Doley & 2009 & $10 / 13$ & $11 / 8$ & $4 / 4$ & Nasojejunal feeding tube, endoscopy \\
Wu & 2010 & - & - & - & Nasojejunal feeding tube, endoscopy \\
\hline
\end{tabular}

TABLE 2: Jadad score.

\begin{tabular}{|c|c|c|c|c|c|}
\hline Authors & Years & Randomized method & Blind & Exit/lost to followup & Jadad scores \\
\hline Louie & 2005 & $\begin{array}{l}\text { 3-center, computer-generated assignment placed in sealed, opaque } \\
\text { envelopes }\end{array}$ & No & Yes & 3 \\
\hline Petrov & 2006 & Computerized random number generation & No & Yes & 3 \\
\hline Gunilla & 2006 & Single-center, sealed, numbered envelopes & No & Yes & 3 \\
\hline Casas & 2007 & Computerized random number generation & No & Yes & 3 \\
\hline Doley & 2009 & Odd/even numbers & No & Yes & 3 \\
\hline $\mathrm{Wu}$ & 2010 & Not mentioned & No & Yes & 2 \\
\hline
\end{tabular}

TABle 3: Effective endpoint of every trial.

(a)

\begin{tabular}{lccccc}
\hline Authors & Years & $\begin{array}{c}\text { No. Patients } \\
(\mathrm{EN} / \mathrm{PN})\end{array}$ & $\begin{array}{c}\text { Pancreatitis-related } \\
\text { complications } \\
\text { (EN/PN) }\end{array}$ & $\begin{array}{c}\text { Non-pancreatitis- } \\
\text { related complications } \\
\text { (EN/PN) }\end{array}$ & $\begin{array}{c}\text { Non-infection-related } \\
\text { complications } \\
(\mathrm{EN} / \mathrm{PN})\end{array}$ \\
\hline Louie & 2005 & $10 / 18$ & $3 / 9$ & $0 / 3$ & $6 / 4$ \\
Petrov & 2006 & $35 / 34$ & $14 / 32$ & $4 / 11$ & $15 / 6$ \\
Gunilla & 2006 & $24 / 26$ & $9 / 4$ & - & $17 / 7$ \\
Casas & 2007 & $11 / 11$ & $1 / 5$ & - & - \\
Doley & 2009 & $25 / 25$ & $16 / 15$ & - & $41 / 15$ \\
Wu & 2010 & $53 / 54$ & $12 / 39$ & - & - \\
\hline
\end{tabular}

(b)

\begin{tabular}{lccccc}
\hline Authors & Years & MOF (EN/PN) & Mortality (EN/PN) & $\begin{array}{c}\text { Hospital stay } \\
\text { (EN/PN) }\end{array}$ & $\begin{array}{c}\text { Surgery intervention } \\
\text { (EN/PN) }\end{array}$ \\
\hline Louie & 2005 & $7 / 13$ & $0 / 3$ & - & - \\
Petrov & 2006 & $7 / 17$ & - & $1 / 0$ & - \\
Gunilla & 2006 & $1 / 1$ & $0 / 2$ & $30.2 / 30.7$ & - \\
Casas & 2007 & $0 / 2$ & $5 / 4$ & $42 / 36$ & $0 / 3$ \\
Doley & 2009 & - & $6 / 23$ & $27 / 16$ & $12 / 21$ \\
Wu & 2010 & $8 / 35$ & & & $12 / 43$ \\
\hline
\end{tabular}




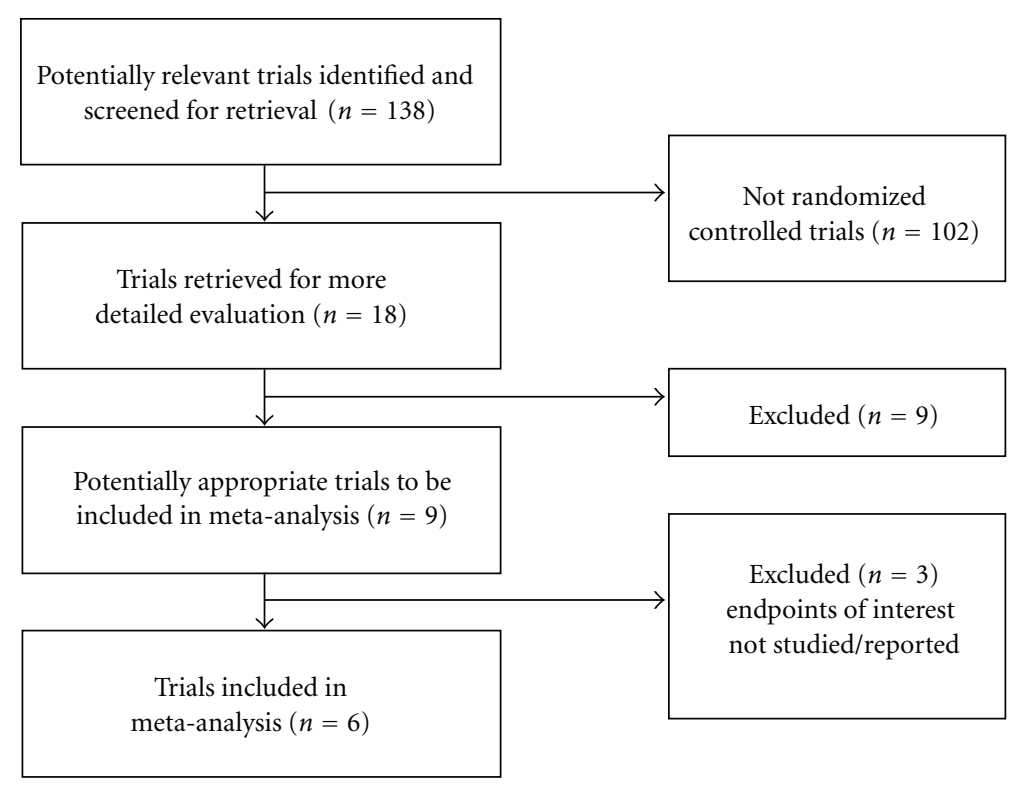

FIgure 1: Process of study selection of RCTs.

random number generation. Blind: all patients were randomized to receive either enteral or parenteral feeding, so none of the studies was blind. Baseline characteristics: all of the six studies reported the baseline characteristics of the two groups, four of which performed statistics analysis. The results indicated that the baseline demographic and clinical characteristics of the two groups were similar. No significant differences were found between the two groups of patients. Loss of followup: all patients in the six studies were hospitalized and followed up during the study. No patients were failed to be followed up. Intention-to-treat analysis and compliance analysis are almost coincident. These characteristics are presented in Figure 1.

3.1. Pancreatitis-Related Complications. All studies reported pancreatitis-related complications, including pancreatic infection, pancreatic abscess, and pancreatic necrosis, not including infections out of pancreas. By $\mathrm{M}-\mathrm{H}$ analysis, there was a significantly lower risk of infection in patients who received enteral nutrition compared to those who received parenteral nutrition (relative risk of $0.556,95 \%$ confidence interval 0.436 to $0.709, P=.000$, Figure 2). The test result for heterogeneity between the studies was not significant $(P=.13006252)$.

3.2. Non-Pancreatitis-Related Complications. All studies reported non-pancreatitis-related complications, including pneumonia, urinary system infection, and central venous catheter infection. By M-H analysis, there was no statistic significance in non-pancreatitis-related complications in patients who received enteral nutrition compared to those who received parenteral nutrition (relative risk of 0.853 , $95 \%$ confidence interval 0.490 to $1.483, P=.017$, Figure 3 ). The test result for heterogeneity between the studies was not significant $(P=.826279278)$.

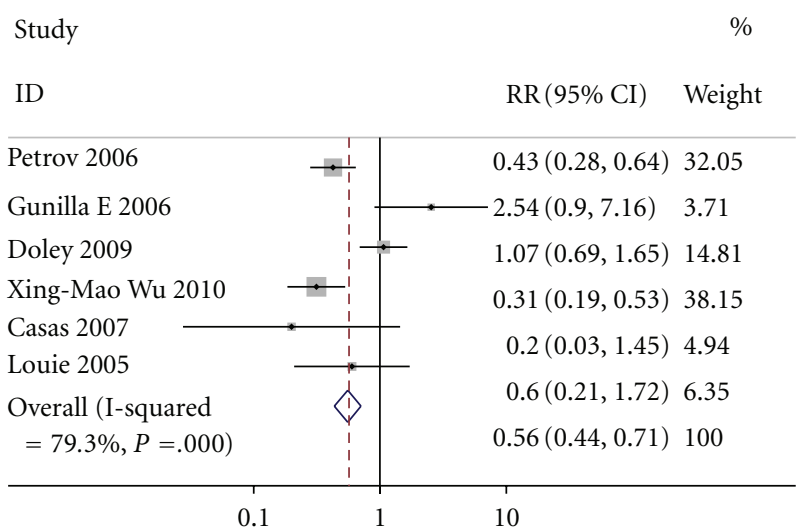

Figure 2

3.3. Non-Infection-Related Complications. Except for Casas and Doley, four of the six studies intimately reported noninfection-related complications, including adult respiratory distress syndrome, pancreatic cyst and fistula, diarrhea, abdominal bloating, and remove of nasal jejunal tube, not including MOF By $\mathrm{M}-\mathrm{H}$ analysis, there was a significantly higher risk in patients who received enteral nutrition compared to those who received parenteral nutrition (relative risk of $2.697,95 \%$ confidence interval 1.947 to $3.735, P=$ .994 , Figure 4$)$. The test result for heterogeneity between the studies was significant $(P=.008212507)$.

3.4. MOF. Except for Doley, five of the six studies intimately reported MOF, By $\mathrm{M}-\mathrm{H}$ analysis, there was a significantly lower risk of mortality in patients who received enteral nutrition compared to those who received parenteral nutrition (relative risk of $0.395,95 \%$ confidence interval 0.272 to 0.573 , 

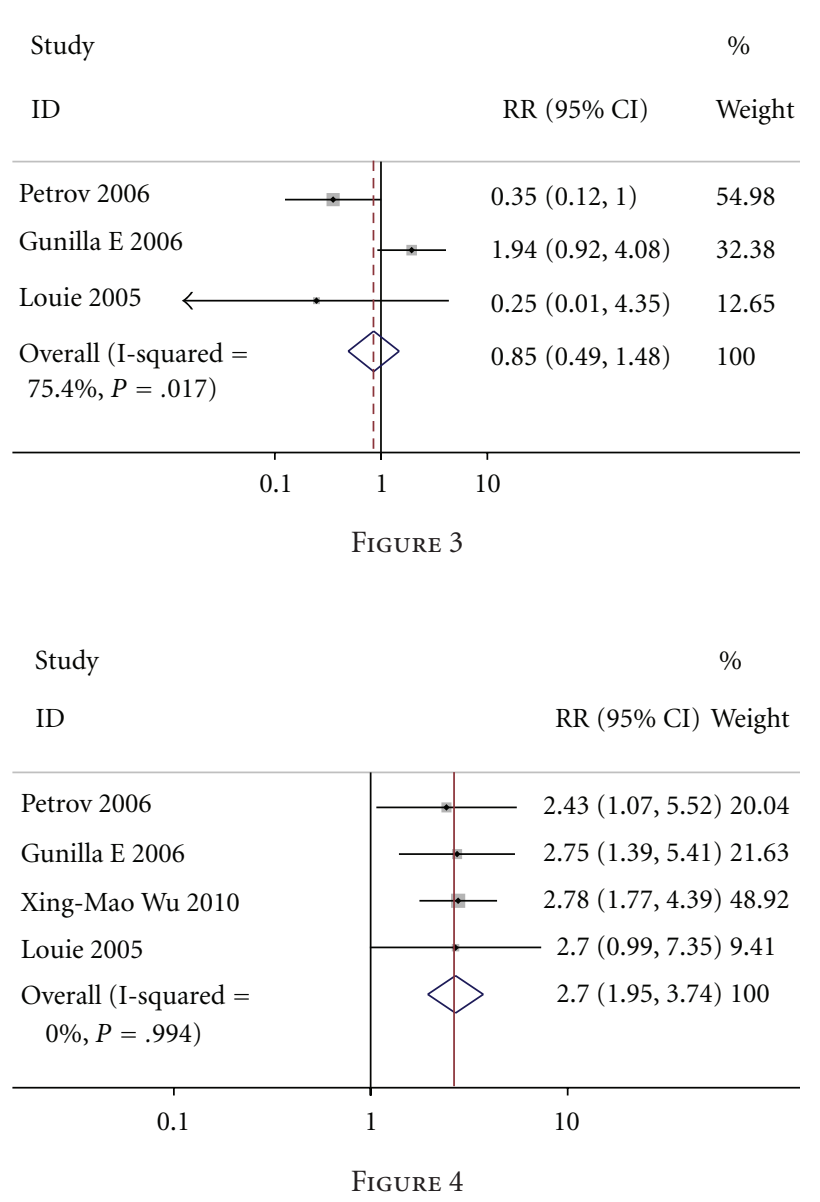

$P=.003$, Figure 5). The test result for heterogeneity between the studies was not significant $(P=.307088503)$.

3.5. Surgical Interventions. Except for Casas, Doley, and $\mathrm{Wu}$, three of the six studies intimately reported surgical interventions. By $\mathrm{M}-\mathrm{H}$ analysis, there was a significantly lower risk of surgical interventions in patients who received enteral nutrition compared to those who received parenteral nutrition (relative risk of $0.501,95 \%$ confidence interval 0.378 to $0.663, P=.000$, Figure 6$)$. The test result for heterogeneity between the studies was not significant $(P=$ .440677966).

3.6. Mortality. Except for Petrov, five of the six studies intimately reported mortality. By M-H analysis, there was a significantly lower risk of mortality in patients who received enteral nutrition compared to those who received parenteral nutrition (relative risk of $0.426,95 \%$ confidence interval 0.238 to $0.764, P=.167$, Figure 7 ). The test result for heterogeneity between the studies was not significant $(P=$ .190278767).

3.7. Hospital Stay. Three of the six studies intimately reported hospital stay. This index is continuous variable. The two groups could not be compared because most of the studies did not provide intimate standard deviation.

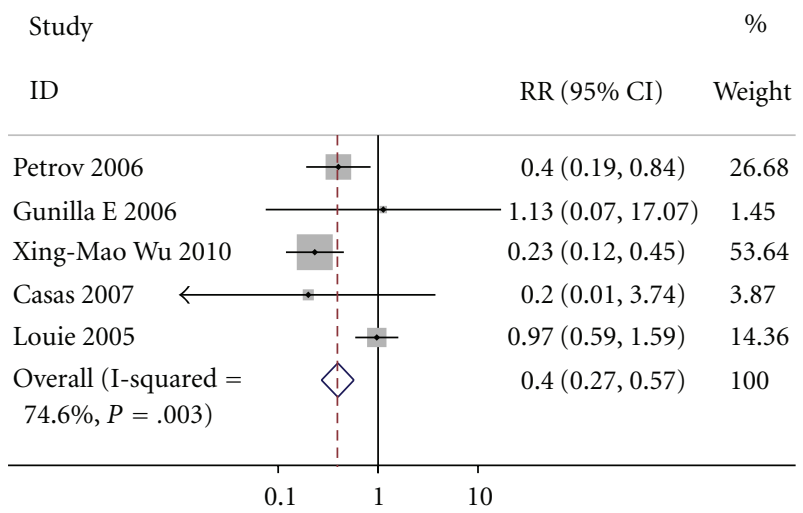

Figure 5

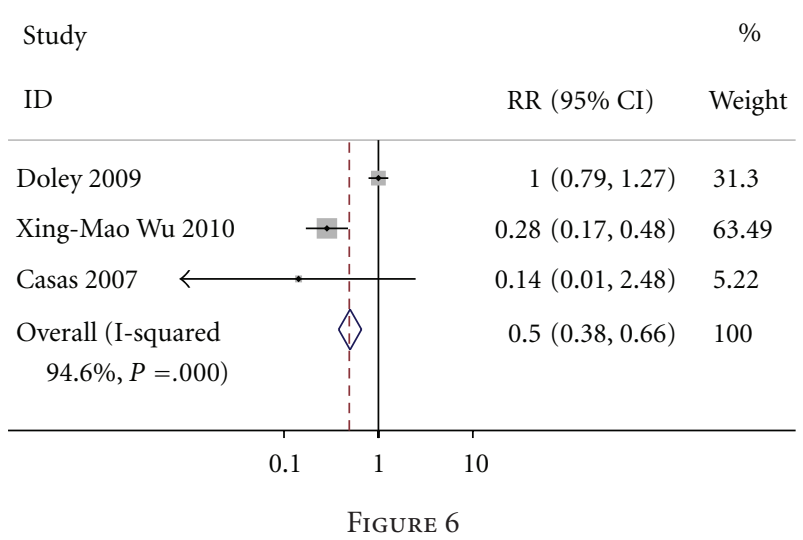

But according to the average hospital stay, there was no significant difference in hospital stay between the two groups. This result was also found in other studies $[27,28]$.

3.8. EN Regimen and Time. Except for Doley and Casas, the other papers all used semielemental nutrition as EN regimen. Most of them infused the nutrition at $25 \mathrm{~mL} / \mathrm{h}$ and increased by $10 \mathrm{~mL} / \mathrm{h}$ every 6 hours. Three of them initiate EN within 24 hours. EN was given for more than seven days in all the six papers (Table 4 ).

\section{Discussion}

This meta-analysis shows that EN, compared with $\mathrm{PN}$, has important beneficial effects in patients with predicted severe acute pancreatitis, notably, clinically relevant, and statistically significant risk reduction in pancreatitis-related complications, non-pancreatitis-related complications, multipleorgan failure (MOF), surgery intervention, and mortality. But PN is superior to EN in non-infection-related complications. There is no difference between EN and PN in hospital stay. The literatures included in this meta-analysis, except for $\mathrm{Wu}$, are all high-quality randomized controlled trials with Jadad score more than three and summarizing the best available evidence-based data. The statistic characterizations of the population and the inclusion/exclusion criteria of 
TABLE 4: EN regimen and time.

\begin{tabular}{|c|c|c|c|c|}
\hline Author & Year & EN regimen & Initial time & Lasting time \\
\hline Louie & 2005 & $\begin{array}{l}\text { A semielemental product with low fat content was infused at } 25 \mathrm{~mL} / \mathrm{h} \text { and } \\
\text { increased by } 10 \mathrm{~mL} / \mathrm{h} \text { every } 6 \text { hours, until the target rate was achieved }\end{array}$ & Within $24 \mathrm{~h}$ & 10 days \\
\hline Petrov & 2006 & $\begin{array}{l}\text { Semielemental nutrition was commenced at a rate of } 25 \mathrm{~mL} / \mathrm{h} \text { and increased } \\
\text { by } 10 \mathrm{~mL} / \mathrm{h} \text { every } 6 \mathrm{~h} \text {, until the desired caloric intake was reached }\end{array}$ & Within $48 \mathrm{~h}$ & $\begin{array}{l}\text { More than } 7 \\
\text { days }\end{array}$ \\
\hline Gunilla & 2006 & $\begin{array}{l}\text { Semielemental nutrition rate was } 25 \mathrm{~mL} / \mathrm{hr} \text { and gradually increased daily up } \\
\text { to } 100 \mathrm{~mL} / \mathrm{hr} \text { if tolerated and needed. The aim was to reach full nutrition } \\
\text { within } 72 \text { hours }\end{array}$ & Within $24 \mathrm{~h}$ & 10 days \\
\hline Casas & 2007 & $\begin{array}{l}\text { Polymeric diet infusion rate was } 25 \mathrm{~mL} / \mathrm{h} \text { with increases of } 25 \mathrm{~mL} / 4 \mathrm{~h} \text { until } \\
\text { requirements were reached }\end{array}$ & Within $72 \mathrm{~h}$ & $\begin{array}{l}\text { More than } 10 \\
\text { days }\end{array}$ \\
\hline Doley & 2009 & Not mentioned & Within $72 \mathrm{~h}$ & $\begin{array}{l}\text { More than } 14 \\
\text { days }\end{array}$ \\
\hline $\mathrm{Wu}$ & 2010 & Semielemental nutrition was given at $20 \mathrm{~mL} / \mathrm{h}$ for 20 hours & Within $24 \mathrm{~h}$ & 16 days \\
\hline
\end{tabular}

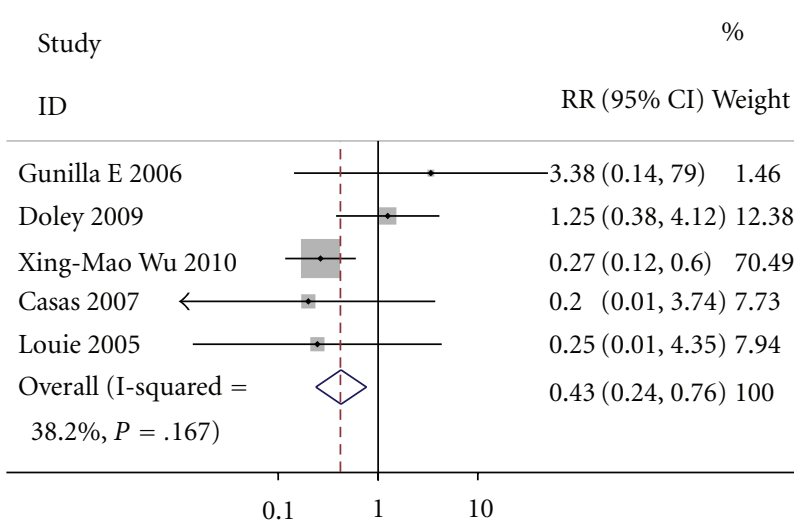

Figure 7

severe acute pancreatitis patients are also the same: (1) abdominal pain, (2) pancreatic enzymes three times higher than normal, and (3) APACHE II score $\geq 8$. Patients in the two groups have no difference in age and gender. Their diseases are mostly caused by cholelithiasis and alcohol pancreatitis. This meta-analysis contains seven outcomes of effectiveness.

\subsection{Pancreatitis-Related Complications and Non-Pancreatitis-} Related Complications. To date, there is a substantial scientific evidence that enteral feeding is superior to total parenteral nutrition (TPN) $[29,30]$. The beneficial effects of enteral feeding on mucosal integrity and the prevention of bacterial overgrowth may well explain the superiority of enteral feeding over TPN. Enteral feeding significantly reduces the risk of infections, lowers the need for surgical interventions, and reduces the length of hospital stay. In the past few years, it has been proposed that EN through nasogastric (NG) tubes may be a simple, safe, and equally valid alternative to nasojejunal tubes, with the potential advantage of earlier administration of nutrients. However, NG feeding cannot be recommended at this time, and it is not clear if a subgroup of SAP patients may benefit more from this approach [31-35].
The facts that EN is most likely superior to parenteral nutrition in preventing septic complications of acute pancreatitis, may also eliminate some complications of PN (catheter sepsis, pneumothorax, and thrombosis), and costs only $15 \%$ of the cost of TPN, make it an increasingly accepted treatment modality [36]. Windsor et al. randomized 34 patients to TPN or enteral nutrition for 7 days. They reported that the reduction in inflammatory response with enteral nutrition could be ascribed to the suppression of bacterial overgrowth rather than to the reduction in pancreatic injury. This observation was supported by the finding of (1) no increase in screen endotoxin antibodies in the enteral nutrition group as compared to an increase in the TPN group $(P<.05)$ and (2) no difference in CT evaluation of the pancreatic injury after enteral nutrition or TPN. There is accumulating clinical evidence that enteral nutrition can improve survival and reduce the complications accompanying the severe acute pancreatitis. The explanations are complex and related to the fact that (1) enteral nutrition avoids TPN complications, (2) luminal nutrition maintains intestinal health, (3) enteral amino acids are more effective in supporting splanchnic protein synthesis, and (4) enteral nutrition may prevent the progression of multiple organ failure.

Many clinical and experimental studies have demonstrated that TPN can promote more cytokine production compared to EN [37, 38], including IL-6, IL-8, TNF, and CRP. Total parenteral nutrition has failed to show any clinical benefits for the patients, as it cannot protect the gut mucosa. On the contrary, enteral feeding repairs the mucosal damage of fasting. If enteral feeding is given very early, it may preserve epithelial integrity and bacterial ecology, thereby helping to maintain gut barrier function [39]. Doley et al. reported that patients given TPN were more often infected by Grampositive organisms and fungi as compared to those given EN who were more often infected by a Gram-negative organism. This observation has an important bearing on the outcome of severe acute pancreatitis as fungal infection carries a higher risk of mortality. Though proper aseptic precautions were maintained, the occurrence of infections with Grampositive organisms such as Staphylococci in the TPN group suggests that it could be due to the invasion of central line catchers with cutaneous commensals [21]. 
Petrov et al. reported that extrapancreatic infectious complications were more frequent in their study $(22 \%)$ than those in other studies. In addition to the severity of the patients included, this is likely due to the prolonged hospital stay and maintained central venous and urinary catheters. In fact, catheter infection was the most frequent extrapancreatic infectious complication. In their study, $46 \%$ of patients were found to have infections, and the most common organisms were Escherichia coli and Pseudomonas aeruginosa, which is similar to earlier reports. It gives an idea about the possible source of infection. In their series, as well as others, most of the infections were with Gram-negative bacteria, and up to one-third of infections in their study were polymicrobial. This would suggest that the gut was the most likely source of infection [17].

4.2. Non-Infection-Related Complications. Compared to TPN, TEN has higher risk of non-infection-related complications caused by nutrition support. Although TEN has so many complications, such as diarrhea and abdominal distension, the risk is much lower than septicemia induced by tube. Recently, Karakan et al. reported that beneficial bacteria can reduce diarrhea complications induced by TEN [40]. Anyway, a number of these complications such as tube removal or diarrhea are relatively minor and can often be managed by avoiding liquid and elixir medications that contain sorbitol (for diarrhea) and use of a nasal bridle in patients at risk for tube removal.

4.3. MOF and Mortality. This meta-analysis demonstrates that TEN is superior to TPN in MOF and mortality. But Doley's study got the conclusion that there is no difference in mortality. But totally, we still support the conclusion that TEN is superior to TPN.

4.4. Surgical Interventions. The references included in our study all reported that TEN has less surgical interventions compared to TPN. But Doley's study got the conclusion that there is no difference in surgical interventions. This conclusion may be caused by the severity of the patient's condition.

\section{Disadvantages}

We did not perform sensitivity analysis because there is only on paper with the Jadad score less than two. But there are still many disadvantages in this meta-analysis. First, the population included in the study is small. Second, in Gunilla's study, the nutritional support way was nasogastric feeding tube. One new meta-analysis compared nasogastric feeding tube and nasojejunal feeding tube and showed that there was no difference between the two ways in mortality, hospital stay, infection-related complications, and costs [41]. Third, the total number of patients enrolled was limited $(n=$ 335), which may lead to wide CI. Fourth, it is possible that studies with negative results, which showed no trend in favor of either intervention, may remain unpublished, leading to publication bias.
Taken together, this meta-analysis confirmed previous reports in the literature, especially those from recent years. This study demonstrated that enteral nutritional support is safe and effective when compared to parenteral support. Compared with TPN, EN was associated with a significantly lower incidence of pancreatic infection complications $(\mathrm{RR}=$ $0.556,95 \%$ CI $0.436 \sim 0.709, P=.000)$, MOF $(\mathrm{RR}=0.395$, $95 \%$ CI $0.272 \sim 0.573, P=.003$ ), surgical interventions (RR = $0.556,95 \%$ CI $0.436 \sim 0.709, P=.000)$, and mortality (RR $=$ $0.426,95 \%$ CI $0.238 \sim 0.764, P=.167)$. There was no statistic significance in non-pancreatitis-related complications (RR $=0.853,95 \%$ CI $0.490 \sim 1.483, P=.017)$. However, EN had a significantly higher incidence of non-infection-related complications $(\mathrm{RR}=2.697,95 \% \mathrm{CI} 1.947 \sim 3.735, P=.994)$. There was no significant difference in hospital stay between patients with TPN and EN. However, a deficiency of this study is its retrospective nature and relatively small sample size. Therefore, studies with larger sample sizes should be done to better define the role of enteral nutritional support in the treatment of severe acute pancreatitis.

\section{Acknowledgment}

This work was funded by grants from Shanghai Shen Kang Hospital Management Center-municipal hospital joint research projects leading-edge technology (no. SHDC12010111).

\section{References}

[1] J. T. Modena, L. B. Cevasco, C. A. Basto, A. O. Vicuña, and M. P. Ramírez, "Total enteral nutrition as prophylactic therapy for pancreatic necrosis infection in severe acute pancreatitis," Pancreatology, vol. 6, no. 1-2, pp. 58-64, 2006.

[2] B. Lindkvist, S. Appelros, J. Manjer, G. Berglund, and A. Borgström, "A prospective cohort study of smoking in acute pancreatitis," Pancreatology, vol. 8, no. 1, pp. 63-70, 2008.

[3] H. Pelli, R. Lappalainen-Lehto, A. Piironen, J. Sand, and I. Nordback, "Risk factors for recurrent acute alcohol-associated pancreatitis: a prospective analysis," Scandinavian Journal of Gastroenterology, vol. 43, no. 5, pp. 614-621, 2008.

[4] I. Nordback, H. Pelli, R. Lappalainen-Lehto, S. Järvinen, S. Räty, and J. Sand, "The recurrence of acute alcohol-associated pancreatitis can be reduced: a randomized controlled trial," Gastroenterology, vol. 136, no. 3, pp. 848-855, 2009.

[5] M. C. Winsler, C. Hall., N. J. M. London, and J. P. Neoptolemus, "Relationship of diagnostic serum amylase to aetiology and prognosis in acute pancreatitis," Gut, vol. 33, pp. 982-986, 1992.

[6] E. L. Bradley, "Indications for surgery in necrotizing pancreatitis-a millineal review," Journal of the Pancreas, vol. 1, no. 1, pp. 1-3, 2000.

[7] S. W. Ashley, A. Perez, E. A. Pierce et al., "Necrotizing pancreatitis," Annals of Surgery, vol. 234, no. 4, pp. 572-580, 2001.

[8] M. W. Buchler, B. Gloor, C. A. Müller, H. Friess, C. A. Seiler, and W. Uhl, "Acute necrotizing pancreatitis: treatment strategy according to th status of infection," Annals of Surgery, vol. 232, no. 5, pp. 619-622, 2000. 
[9] J. Slavin, P. Ghaneh, R. Sutton et al., "Management of necrotizing pancreatitis," World Journal of Gastroenterology, vol. 7, no. 4, pp. 476-481, 2001.

[10] R. Flint, J. Windsor, and M. Bonham, "Trends in the management of severe acute pancreatitis: interventions and outcome," ANZ Journal of Surgery, vol. 74, no. 5, pp. 335-342, 2004.

[11] D. Karsenti, P. Bourlier, E. Dorval et al., "Morbidity and mortality of acute pancreatitis. Prospective study in a French university hospital," Presse Medicale, vol. 31, no. 16, pp. 727734, 2002.

[12] D. Fenton-Lee and C. W. Imrie, "Pancreatic necrosis: assessment of outcome related to quality of life and cost of management," British Journal of Surgery, vol. 80, no. 12, pp. 1579-1582, 1993.

[13] B.W. M. Spanier, M. J. Bruno, and E. M. H. MathusVliegen, "Enteral nutrition and acute pancreatitis: a review," Gastroenterology Research and Practice, vol. 2011, pp. 11551153, 2010.

[14] R. F. Meier and C. Beglinger, "Nutrition in pancreatic diseases," Best Practice and Research: Clinical Gastroenterology, vol. 20, no. 3, pp. 507-529, 2006.

[15] R. Meier, J. Ockenga, M. Pertkiewicz et al., "ESPEN guidelines on enteral nutrition: pancreas," Clinical Nutrition, vol. 25, no. 2, pp. 275-284, 2006.

[16] S. J. O'Keefe and S. A. McClave, "Feeding the injured pancreas," Gastroenterology, vol. 129, no. 3, pp. 1129-1130, 2005.

[17] Y. Cao, Y. Xu, T. Lu, F. Gao, and Z. Mo, "Meta-analysis of enteral nutrition versus total parenteral nutrition in patients with severe acute pancreatitis," Annals of Nutrition and Metabolism, vol. 53, no. 3-4, pp. 268-275, 2009.

[18] M. S. Petrov, H. C. Van Santvoort, M. G. H. Besselink, G. J. M. G. Van Der Heijden, J. A. Windsor, and H. G. Gooszen, "Enteral nutrition and the risk of mortality and infectious complications in patients with severe acute pancreatitis: a meta-analysis of randomized trials," Archives of Surgery, vol. 143, no. 11, pp. 1111-1117, 2008.

[19] M. Al-Omran, A. Groof, and D. Wilke, "Enteral versus parenteral nutrition for acute pancreatitis," Cochrane Database of Systematic Reviews, no. 1, Article ID CD002837, 2003.

[20] R. P. Doley, T. D. Yadav, J. D. Wig et al., "Enteral nutrition in severe acute pancreatitis," Journal of the Pancreas, vol. 10, no. 2, pp. 157-162, 2009.

[21] P. E. Marik and G. P. Zaloga, "Meta-analysis of parenteralnutrition versus enteral nutrition in patients with acute pancreatitis," British Medical Journal, vol. 328, no. 7453, pp. 1407-1410, 2004.

[22] X. M. Wu, K. Q. Ji, H. Y. Wang, G. F. Li, B. Zang, and W. M. Chen, "Total enteral nutrition in prevention of pancreatic necrotic infection in severe acute pancreatitis," Pancreas, vol. 39, no. 2, pp. 248-251, 2010.

[23] B. E. Louie, T. Noseworthy, D. Hailey, L. M. Gramlich, P. Jacobs, and G. L. Warnock, "2004 MacLean-Mueller Prize Enteral or parenteral nutrition for severe pancreatitis: a randomized controlled trial and health technology assessment," Canadian Journal of Surgery, vol. 48, no. 4, pp. 298-306, 2005.

[24] G. E. Eckerwall, J. B. Axelsson, and R. G. Andersson, "Early nasogastric feeding in predicted severe acute pancreatitis: a clinical, randomized study," Annals of Surgery, vol. 244, no. 6, pp. 959-965, 2006.
[25] M. S. Petrov, M. V. Kukosh, and N. V. Emelyanov, "A randomized controlled trial of enteral versus parenteral feeding in patients with predicted severe acute pancreatitis shows a significant reduction in mortality and in infected pancreatic complications with total enteral nutrition," Digestive Surgery, vol. 23, no. 5-6, pp. 336-345, 2007.

[26] M. Casas, J. Mora, E. Fort et al., "Total enteral nutrition vs. total parenteral nutrition in patients with severe acute pancreatitis Nutrición enteral total vs. nutrición parenteral total en pacientes con pancreatitis aguda grave," Revista Espanola de Enfermedades Digestivas, vol. 99, no. 5, pp. 264269, 2007.

[27] F. Kalfarentzos, J. Kehagias, N. Mead, K. Kokkinis, and C. A. Gogos, "Enteral nutrition is superior to parenteral nutrition in severe acute pancreatitis: results of a randomized prospective trial," British Journal of Surgery, vol. 84, no. 12, pp. 1665-1669, 1997.

[28] S. A. McClave and G. W. Dryden, "Issues of nutritional support for the patient with acute pancreatitis," Seminars in Gastrointestinal Disease, vol. 13, no. 3, pp. 154-160, 2002.

[29] A. Oláh and L. Romics Jr., "Evidence-based use of enteral nutrition in acute pancreatitis," Langenbeck's Archives of Surgery, pp. 1-8, 2010.

[30] O. Ioannidis, A. Lavrentieva, and D. Botsios, "Nutrition support in acute pancreatitis," Journal of the Pancreas, vol. 9, no. 4, pp. 375-390, 2008.

[31] M. Piciucchi, E. Merola, M. Marignani et al., "Nasogastric or nasointestinal feeding in severe acute pancreatitis," World Journal of Gastroenterology, vol. 16, no. 29, pp. 3692-3696, 2010.

[32] F. C. Eatock, P. Chong, N. Menezes et al., "A randomized study of early nasogastric versus nasojejunal feeding in severe acute pancreatitis," American Journal of Gastroenterology, vol. 100, no. 2, pp. 432-439, 2005.

[33] A. Kumar, N. Singh, S. Prakash, A. Saraya, and Y. K. Joshi, "Early enteral nutrition in severe acute pancreatitis: a prospective randomized controlled trial comparing nasojejunal and nasogastric routes," Journal of Clinical Gastroenterology, vol. 40, no. 5, pp. 431-434, 2006.

[34] G. E. Eckerwall, J. B. Axelsson, and R. G. Andersson, "Early nasogastric feeding in predicted severe acute pancreatitis: a clinical, randomized study," Annals of Surgery, vol. 244, no. 6, pp. 959-965, 2006.

[35] A. A. Samaraee, I. J. D. McCallum, P. E. Coyne, and K. Seymour, "Nutritional strategies in severe acute pancreatitis: a systematic review of the evidence," The Surgeon, vol. 8, no. 2, pp. 105-110, 2010.

[36] A. C. J. Windsor, S. Kanwar, A. G. K. Li et al., "Compared with parenteral nutrition, enteral feeding attenuates the acute phase response and improves disease severity in acute pancreatitis," Gut, vol. 42, no. 3, pp. 431-435, 1998.

[37] D. G. Kelly and C. R. Fleming, "Nutritional considerations in inflammatory bowel diseases," Gastroenterology Clinics of North America, vol. 24, no. 3, pp. 597-611, 1995.

[38] D. B. A. Silk, "Medical management of severe inflammatory disease of the rectum: nutritional aspects," Bailliere's Clinical Gastroenterology, vol. 6, no. 1, pp. 27-41, 1992.

[39] C. Dervenis, "Enteral nutrition in severe acute pancreatitis: future development," Journal of the Pancreas, vol. 5, no. 2, pp. 60-63, 2004.

[40] T. Karakan, M. Ergun, and I. Dogan, "Comparison of early enteral nutrition in severe acute pancreatitis with prebiotic fiber supplementation versus standard enteral solution: a 
prospective randomized double-blind study," Journal of the Pancreas (Online), vol. 10, no. 2, pp. 157-160, 2009.

[41] K. Jiang, X. Z. Chen, Q. Xia, W. F. Tang, and L. Wang, "Early nasogastric enteral nutrition for severe acute pancreatitis: a systematic review," World Journal of Gastroenterology, vol. 13, no. 39, pp. 5253-5260, 2007. 


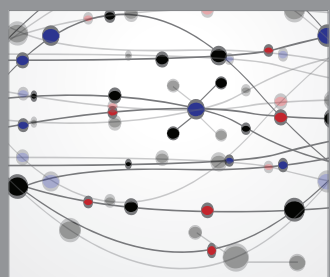

The Scientific World Journal
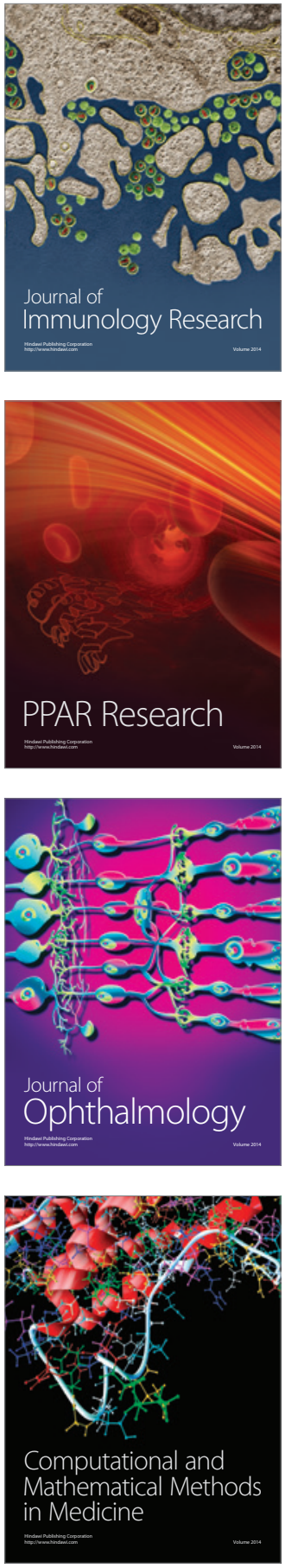

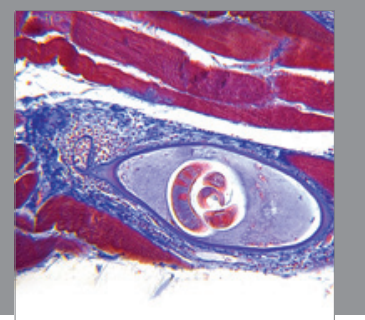

Gastroenterology

Research and Practice
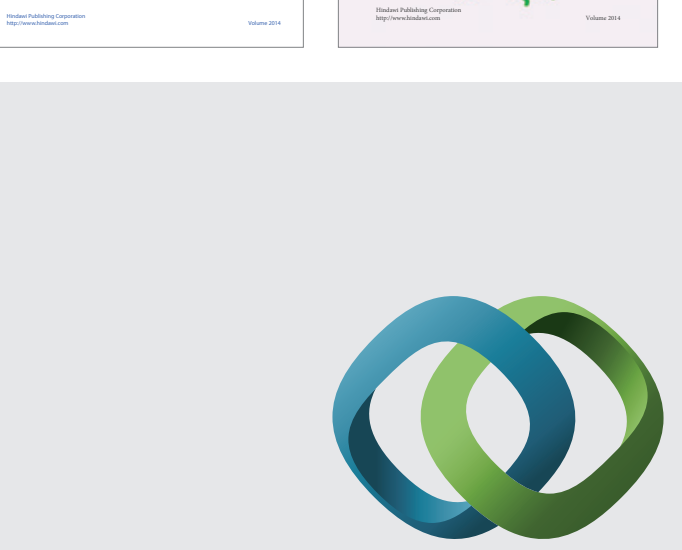

\section{Hindawi}

Submit your manuscripts at

http://www.hindawi.com
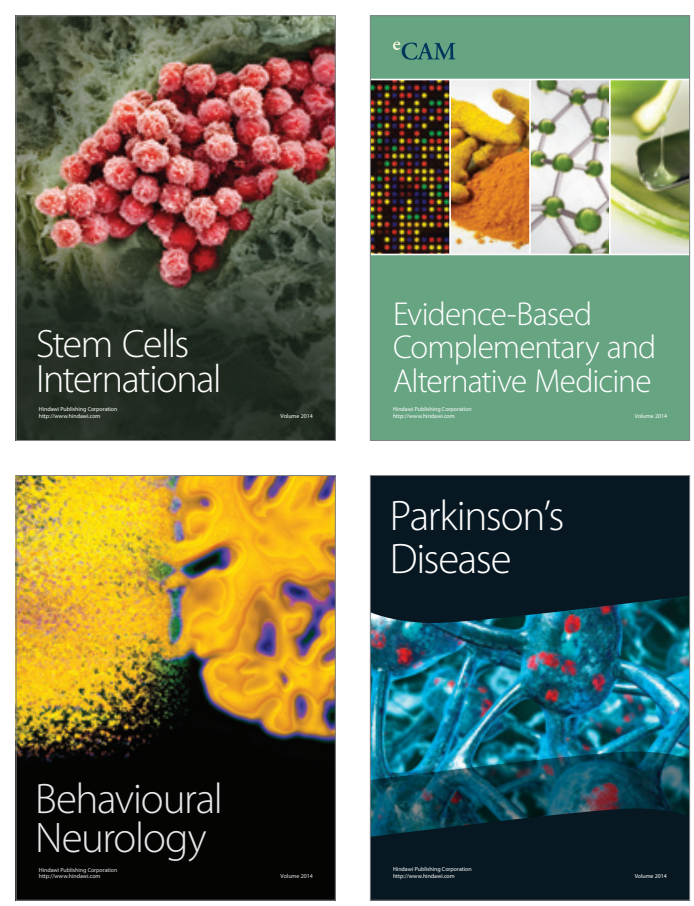

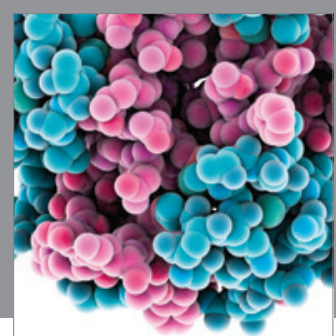

Journal of
Diabetes Research

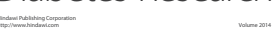

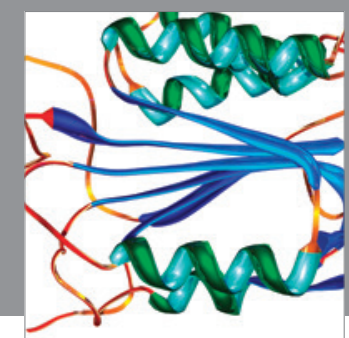

Disease Markers
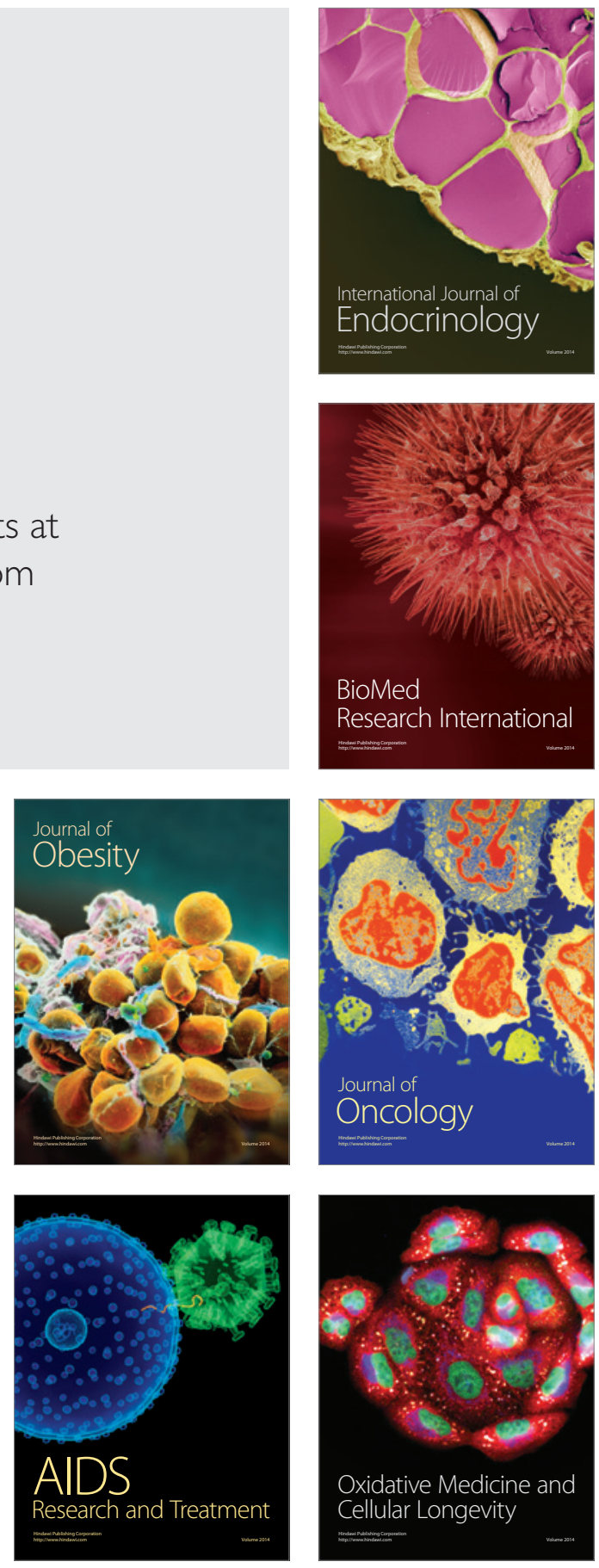